\title{
O076: Impact of the implementation of the who hand hygiene promotion strategy in the Hong Kong pilot site: 2006-2012
}

\author{
JWM Tai ${ }^{1 *}$, D Pittet ${ }^{2}$, WH Seto ${ }^{3}$, V Cheng ${ }^{4}$, P Ching $^{5}$ \\ From 2nd International Conference on Prevention and Infection Control (ICPIC 2013) \\ Geneva, Switzerland. 25-28 June 2013
}

\section{Introduction}

The WHO First Global Patient Safety Challenge "Clean Care is Safer Care" aims to tackle healthcare-associated infection worldwide with hand hygiene $(\mathrm{HH})$ as the cornerstone intervention.

\section{Objectives}

To assess the impact and sustainability of the WHO hand hygiene multimodal improvement strategy in the Hong Kong pilot site hospital.

\section{Methods}

Times series design with experimental and control wards. Data were collected during three cycles of action research targeted at improving compliance with practices.

\section{Results}

Overall hand hygiene compliance was 22\% (experimental wards, 18.3\%; controls, 25.4\%) at baseline. At the end of the first action research cycle (April-Dec 2006), compliance improved to $41.6 \%$ in experimental wards and decreased to $18.8 \%$ in control wards. When multimodal interventions were extended to six study sites in the second action research cycle (Jan-May 2007), experimental wards showed sustainability (44.4\%), while no change was observed in control wards (25.6\%). During the last action research cycle (May 07- Feb 2008), overall compliance increased to $54 \%$ (experimental wards, $52.6 \%$; controls, $55.3 \%)$. Further reinforcement strategies were implemented from March 2008 and overall hospital compliance increased to $78.6 \%$ in 2012. In parallel, the use of alcohol-based handrub increased from $2 \mathrm{~L} / 1000$ patient-days in 2006 to $45 \mathrm{~L} / 1000$ patient-days in 2012. Methicillinresistant Staphylococcus aureus bloodstream infection decreased from 1.53/1'000 patient-days in 2006 to 0.87 / $1^{\prime} 000$ patient-days in 2012.

\section{Conclusion}

The WHO HH promotion strategy, using an action research approach, is successful with sustained compliance and continuous reduction in MRSA bloodstream infection rates.

\section{Disclosure of interest}

None declared.

\section{Author details}

'Infection Control, Queen Mary Hospital, Hong Kong, China. ${ }^{2}$ Infection Control, University of Geneva Hospitals, Geneva, Switzerland. ${ }^{3}$ WHO Collaborating Centre, Hong Kong, Hong Kong. ${ }^{4}$ Queen Mary Hospital, Hong Kong, Hong Kong. ${ }^{5} \mathrm{WHO}$ Collaborating Centre, Hong Kong, Hong Kong.

Published: 20 June 2013

doi:10.1186/2047-2994-2-S1-076

Cite this article as: Tai et al:: O076: Impact of the implementation of the who hand hygiene promotion strategy in the Hong Kong pilot site: 2006-2012. Antimicrobial Resistance and Infection Control 2013 2(Suppl 1): 076.

IInfection Control, Queen Mary Hospital, Hong Kong, China

Full list of author information is available at the end of the article

(C) 2013 Tai et al; licensee BioMed Central Ltd. This is an Open Access article distributed under the terms of the Creative Commons 